\title{
FIJACIÓN BIOLÓGICA DE NITRÓGENO EN ARVEJA (PISUM SPP) MEDIANTE TÉCNICAS ISOTÓPICAS DEL N15, EN UN SUELO ANDISOL, LLANO GRANDE CARTAGO, COSTA RICA.
}

\author{
Paola Brenes Rojas ${ }^{1}$, Wagner Peña Cordero ${ }^{2+}$ \\ ${ }^{1}$ Vicerrectoría de Investigación UNED, paolaris@gmail.com \\ ${ }^{2}$ Encargado de Catedra de gestión sostenible del Suelo Escuela de Ciencias Exactas y Naturales. UNED, \\ wpena@uned.ac.cr
}

Universidad Estatal a Distancia. Costa Rica

\begin{abstract}
Resumen
El nitrógeno es el nutriente de mayor demanda y clave en los cultivos, por lo que escasez de este elemento limita la producción. La arveja (Pisum sativum L.) tiene la capacidad de fijar nitrógeno y es considerada una de las menos eficientes (70-300 kg/ha/año) es por ello por lo que se plantea la necesidad de mejorar el rendimiento del cultivo y de determinar la potencialidad de fijación de nitrógeno de la especie. El estudio se llevó a cabo en La Angelina, de Cartago. Se trabajó con la arveja (Pisum sativum) como cultivo principal del estudio. Primeramente, se ejecutó un ensayo en el 2016 para determinar la fijación bilógica de nitrógeno $(\mathrm{FBN})$ y en el 2017 se repitió la valoración de la FBN, incluyendo un tratamiento con la inoculación en el sustrato de Azotobacter vinelandii y otro sin inocular la bacteria. Entre los resultados obtenidos los mejores resultados se presentaron cuando la arveja (Pisum spp), fue inoculada con azotobacter (Fabaceae + Azotobacter) con una cantidad de nitrógeno fijado en el caso del maíz de 26,38\%, gracias a que la mayor contribución de nitrógeno fijado en los ecosistemas terrestres proviene de la asociación con diferentes géneros de bacterias, en cultivos como Maíz, y Amaranthus fue de (24,78 y 28,93\%), de nitrógeno fijado respectivamente. Se concluye que alternativas sostenibles lograrían minimizar el impacto, como es el uso de plantas con capacidad de fijación biológica del nitrógeno (FBN), mayormente representado por leguminosas que fijan entre 90 y $450 \mathrm{~kg} \mathrm{~N} / \mathrm{ha}$.
\end{abstract}

Palabras claves: Leguminosas, Inoculación, Azotobacter, Abono verde.

\begin{abstract}
Nitrogen is the most demanded and key nutrient in crops, so a shortage of this element limits production. Pea (Pisum sativum L.) has the ability to fix nitrogen and is considered one of the least efficient crops $(70-300 \mathrm{~kg} / \mathrm{ha} /$ year), therefore there is a need to improve crop yield and determine the nitrogen fixation potential of the species. The study was carried out in La Angelina, in Cartago, Costa Rica. Pea (Pisum sativum) was used as the main crop of the study. First, a trial was run in 2016 to determine the biological nitrogen fixation (BNF) and in 2017 the assessment of BNF was repeated, including a treatment with inoculation on the Azotobacter vinelandii substrate and another without inoculating the bacteria. Among the results obtained, the best results were presented when the pea (Pisum spp) was inoculated with azotobacter (Fabaceae + Azotobacter) with an amount of nitrogen fixed in the case of corn of $26.38 \%$, thanks to the greater contribution of Nitrogen fixed in terrestrial ecosystems comes from the association with different genera of bacteria, in crops such as Corn, and Amaranthus was (24.78 and 28.93\%), of fixed nitrogen respectively. It is concluded that sustainable alternatives would manage to minimize the impact, such as the use of plants with biological nitrogen fixation capacity (BNF), mainly represented by legumes that fix between 90 and $450 \mathrm{~kg} \mathrm{~N} /$ ha.
\end{abstract}




\section{Introducción}

A pesar de que la arveja tiene la capacidad de fijar nitrógeno es considerada una de las menos eficientes (70$300 \mathrm{~kg} / \mathrm{ha} /$ año) según Hardarson et al. 1987 y Urzúa 2000. Este cultivo necesita de fertilización nitrogenada adicional para alcanzar mejores rendimientos cuando el suministro de $\mathrm{N}$ del suelo, en especial cuando lo suelos tienen escases importantes de este elemento (Ursúa, 2000).

El nitrógeno es el nutriente de mayor demanda y clave en los cultivos, ya que es un componente principal de múltiples organelas esenciales en las plantas, y además es elemental en los procesos de desarrollo de la planta (Rao, 2009); por lo que escasez de este elemento limita la producción. Una fertilización adecuada y eficiente les permite a los sistemas productivos, tener buenos rendimientos (Vessey, 2002).

Es por ello por lo que se plantea la necesidad de mejorar el rendimiento del cultivo y de determinar la potencialidad de fijación de nitrógeno de la especie asociada a otros microrganismos que promueva mayor fijación de nitrógeno como es el caso del azotobacter. El azotobacter es conocido como unas bacterias fijadoras de nitrógeno de vía libre, es decir de que no necesita de una relación simbiótica para realizar el proceso de captura del nitrógeno gaseoso para reducir a un nitrógeno asimilable por la planta como el NH4+.

\section{Materiales y métodos}

El estudio se está llevó a cabo en sitio conocido como La Angelina, su ubicación es : Latitud 9.928492, longitud -83.929805, distrito de Llano Grande, cantón central de Cartago, Costa Rica.

Esta finca se encuentra en la cuenca número nueve del Reventazón, a una altura de $1.300 \mathrm{msnm}$ y en un tipo de suelo andisol, con una pendiente de 1-12\%. La determinación de los análisis químicos y microbiológicos iníciales del suelo se realizó en el Instituto Nacional de Trasferencia Agropecuaria (INTA) de la Universidad de Costa Rica y en el Instituto Nacional de Aprendizaje (INA), y las muestras para determinar los valores de N15, fueron enviadas a un laboratorio especializada de la Universidad de Florida. Este sustrato se colocó en 30 macetas para realizar el estudio, con cinco macetas por cultivo, colocadas en fila. La investigación se inició el lunes 20 de febrero de 2017, y se utilizó una dosis de siembra de 10 semillas por maceta. 


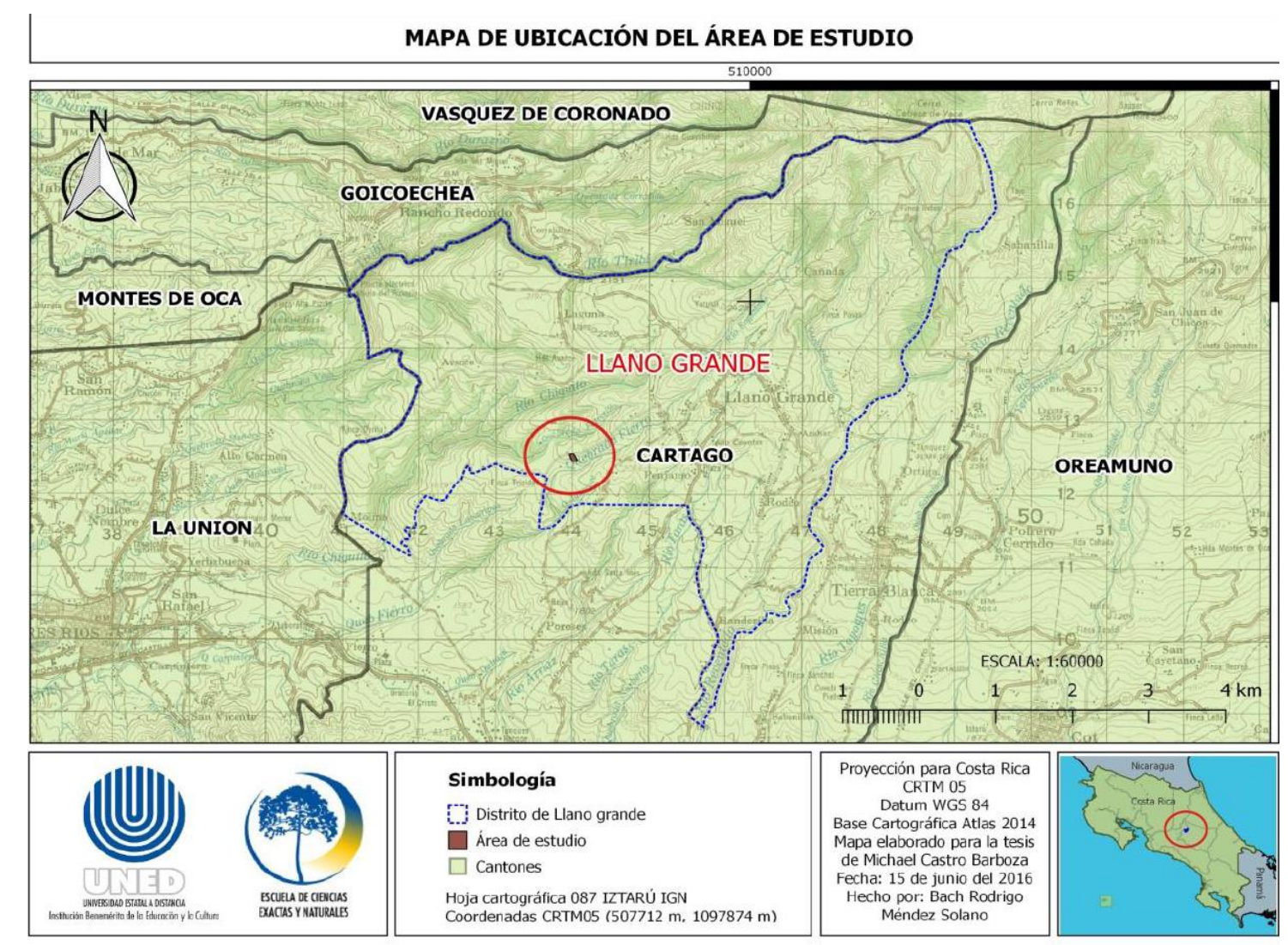

Figura 1. Sitio de estudio. Finca Brenes, Cartago, Costa Rica

Fuente: Méndez, 2016

Se trabajó con la arveja (Pisum sativum) como cultivo principal del estudio. Primeramente, se ejecutó un ensayo en el 2016 para determinar la fijación bilógica de nitrógeno (FBN) y en el 2017 se repitió la valoración de la FBN, incluyendo un tratamiento con la inoculación en el sustrato de Azotobacter vinelandii y otro sin inocular la bacteria. Se usan cinco cultivos de referencia en un diseño de bloques completamente al azar con tres repeticiones. Los cultivos de referencia seleccionados corresponden a maíz (Zea mays), quinua (Chenopodium quinoa), sorgo (Sorguhum bicolor), arroz (Oriza sativa) y abdalay (Coix lacryma jobi). El estudio se basa en los trabajos de Wagner y Zapata, 1982; Androssf et al, 1995 y Valles de la Mora et al, 2003.

El nitrógeno marcado se aplicó como urea con $9.381 \%$ átomos en exceso en el 2016 y al $5.00 \%$ en el 2017 en dosis de $10 \mathrm{~kg} \mathrm{~N}$ ha-l. En el 2016 el estudio se hizo a campo abierto sobre el campo y en el 2017 se condujo en macetas. El nitrógeno marcado isotópicamente se aplicó diluido al suelo, tratando de uniformizar la cantidad em todo el área o maceta.

La producción de materia seca (MS), se evaluó en cada parcela y maceta, la cual se cortó antes de la floración, a $2 \mathrm{~cm}$ del sustrato. Las muestras de materia verde constituyen todo el material vegetal y se pesarón por separado. Luego se secarón en horno con ventilación forzada de aire a $65^{\circ} \mathrm{C}$ hasta alcanzar peso constante, para determinar su contenido de materia seca (MS). En cada muestra de material vegetal se analizó el $\mathrm{N}$ total, según Kjeldahl, y la relación isotópica N15 14N-1 (Espectrometría de masa) Para el cálculo del N fijado por la 
leguminosa se usará el método de dilución isotópica del N15 (Hardarson y Danso, 1990 y Danso, 1995). Los datos obtenidos fueron sometidos a análisis de varianza y si hay diferencias significativas, se utilizará la Prueba de Tukey, para comparación de las medias de tratamiento, usando el programa estadístico INFOSTAT (Di Rienzo, Casanoves, Balzani, Tablada y Robledo2011).

La fórmula para determinar la fijación biológica de nitrógeno atmosférico (puede ser simbiótica o asimbiótica) usando método isotópico marcando el suelo con fertilizante nitrogenado marcado con $15 \mathrm{~N}$ (*), es:

$$
\% \text { Nfix }=\left[1-\frac{\% 15 \text { Nleg }}{\% 15 \mathrm{~N} \text { Pl.control }}\right] \times 100
$$

Nfix $=\mathrm{N}$ fijado

Pl.control $=$ planta padrón $($ planta no fijadora $)$

Usar siempre valores de \% $15 \mathrm{~N}$ en exceso, o sea, $\% 15 \mathrm{~N}-0,366$

leg = leguminosa

\section{Resultados y discusión}

Según el INTA (2016), las legumbres como el caso de la arveja (Pisum spp), son una opción, alternativa y sustentable que permite el enriquecimiento del suelo y de los cultivos en asocio, esto gracias a la capacidad que tienen estas legumbres de fijar nitrógeno del aire.

De los tratamientos utilizados, se observa que los mejores resultados se dieron entre la asociación Fabaceae + Azotobacter, teniendo los mejores resultados en el promedio de $\mathrm{N}$ absorbido del aire (76,70 kg/ha), así como de la cantidad de $\mathrm{N}$ fijado y recuperado del suelo $(19,41$ y 57,29 $\mathrm{kgN} / \mathrm{ha}$ respectivamente), comparado al tratamiento donde solo se utilizo la Fabaceae sin inocular.

Al comparar ambos tratamientos sin duda alguna se observa que fue más efectiva y eficiente los resultados cuando se trabajó con la inoculación de la bacteria Azotobacter, teniendo incrementos en los valores de promedio de $\mathrm{N}$ absorbido del aire $(44,15 \%)$, así como de la cantidad de $\mathrm{N}$ fijado y recuperado del suelo (72,23 y 34,63\% respectivamente), comparado al tratamiento donde solo se utilizó la Fabaceae sin inocular.

Los mejores resultados se presentaron cuando la arveja (Pisum spp), fue inoculada con azotobacter (Fabaceae + Azotobacter) con una cantidad de nitrógeno fijado en el caso del maíz de 26,38\% (cuadro 1), gracias a que la mayor contribución de nitrógeno fijado en los ecosistemas terrestres proviene de la asociación con diferentes géneros de bacterias. Como el caso de las bacterias del género Azotobacter. 
Según los mencionado por Chaves (2016), las bacterias juegan un papel de gran importancia, debido a que son fundamentales en el reciclaje de nutrimentos, estas bacterias pueden actuar de manera simbiótica y no asimbiótica, una de las principales funciones de estos organismos es la de fijar nitrógeno atmosférico por eso se da una mayor eficacia en la transferencia de este nitrógeno fijado a las diferentes plantas de control, cuando se dio la inoculación de la arveja con bacterias del género Azotobacter. .

Cuadro 1. Fijación biológica de la Arveja inoculada con Azotobacter y sin inoculación con parado con tres plantas control.

\begin{tabular}{lllllll}
\hline Tratamiento & $\begin{array}{l}\% \mathrm{~N} \\
\text { fix } \\
\text { maiz }\end{array}$ & $\begin{array}{l}\% \mathrm{~N} \text { fixm } \\
\text { con coix }\end{array}$ & $\begin{array}{l}\text { Promedio de } \% \\
\text { N fix quinua }\end{array}$ & $\begin{array}{l}\text { Promedio de Cuando absorbió } \\
\text { de N suelo y aire }(\mathrm{Kg} / \mathrm{ha})\end{array}$ & $\begin{array}{l}\text { QNPFIX } \\
\text { (kgN/ha) }\end{array}$ & $\begin{array}{l}\text { QNPDFS } \\
\text { (kgN/ha) }\end{array}$ \\
\hline Fabaceae & 12,23 & 5,38 & $-6,62$ & 42,84 & 5,38 & 37,45 \\
$\begin{array}{l}\text { Fabaceae+ } \\
\text { Azotobacter }\end{array}$ & 26,38 & 20,64 & 10,56 & 76,70 & 19,41 & 57,29 \\
\hline
\end{tabular}

QNPFIX: cantidad de Nitrógeno fijado.

QNPDFS: cantidad de nitrógeno recuperado del suelo.

N fix: Nitrógeno Fijado por el cultivo.

En el cuadro 2, se observa que los mejores resultados se presentaron en los cultivos de Maíz, y Amaranthus con ( 24,78 y $28,93 \%)$, de nitrógeno fijado respectivamente, por ende, existió valores más altos de aprovechamiento de $\mathrm{N}$ a través del nitrógeno fijado por el cultivo de arveja.

Estos valores más altos en estos cultivos específicos como el maíz y el Amaranthus, se pueden decir que por efecto y según los expresado por Paredes (2013), que la Fijación Biológica de Nitrógeno (FBN) es el proceso por el cual los microorganismos aprovechan el nitrógeno que se encuentra en el aire, para convertirlo a amoniaco por medio de una enzima de nombre nitrogenasa y convertirlo en proteínas. Estos microorganismos llamados fijadores de nitrógeno son bacterias y cianobacterias que viven libres en el suelo, asociadas a algunas plantas, por lo cual se dio un mayor aprovechamiento en estos dos cultivos.

También estos resultados se pueden deber a lo mencionado por Hernán y Castellanos (2011), en el que expresa que los factores como la temperatura y la humedad óptimas para el crecimiento bacteriano no siempre se presentan al mismo tiempo en los ecosistemas, por lo que las tasas de descomposición y mineralización de la materia orgánica se llevan a cabo principalmente en periodos cortos de tiempo e irregulares en un periodo dado, incidiendo en el promedio de nitrógeno fijado en cada cultivo. 
Cuadro 2. Fijación biológica de la Arveja inoculada con Azotobacter y sin inoculación con parado con tres plantas control

\begin{tabular}{|c|c|c|c|c|c|c|}
\hline $\begin{array}{l}\text { Etiqu } \\
\text { etas } \\
\text { de } \\
\text { fila }\end{array}$ & $\begin{array}{lr}\text { Promedio de } \% \mathrm{~N} \\
\text { fijado } & \text { contra } \\
\text { planta } & \text { control } \\
\text { Rábano } & \end{array}$ & $\begin{array}{l}\text { Promedio de } \% \mathrm{~N} \\
\text { fijado } \quad \text { contra } \\
\text { planta } \\
\text { maiz }\end{array}$ & $\begin{array}{l}\text { Promedio } \\
\text { de } \% \mathrm{~N} \\
\text { fijado } \\
\text { Amaranthus }\end{array}$ & $\begin{array}{l}\text { Promedio } \\
\text { Cuando absorbió } \\
\text { de N suelo y aire } \\
\mathrm{kg} / \mathrm{ha}\end{array}$ & $\begin{array}{l}\text { Prome } \\
\text { dio de } \\
\text { Qnpdfi } \\
x\end{array}$ & $\begin{array}{l}\text { Promed } \\
\text { io de } \\
\text { QNPD } \\
\text { FS }\end{array}$ \\
\hline $\begin{array}{l}\text { Arvej } \\
\mathrm{a}\end{array}$ & $-84,79$ & 24,78 & 28,93 & 14,61 & 3,74 & 10,87 \\
\hline
\end{tabular}

QNPFIX: cantidad de Nitrógeno fijado.

QNPDFS: cantidad de nitrógeno recuperado del suelo.

$\mathrm{N}$ fix: Nitrógeno fijado por el cultivo.

\section{Conclusiones}

Las bacterias juegan un papel importante en los diferentes agroecosistemas, debido a su capacidad y eficiencia en el reciclaje de nutrimentos y transferencia de nitrógeno que es fijado a la misma, de ahí que la fijación simbiótica de nitrógeno es una alternativa viable.

Alternativas sostenibles como el caso del uso de la arveja como planta leguminosa fijadora de nitrógeno permite lograr minimizar el impacto en el medioambiente, siendo una alternativa sustentable, y con mayor eficacia en el aprovechamiento del nitrógeno.

Los factores edafoclimáticos son claves en la fijación biológica de nitrógeno, debido a que estos factores inciden de forma directa en el aprovechamiento de nitrógeno fijado de los cultivos, además de que depende de la asociación simbiótica que se presente.

\section{Bibliografía}


Chaves, E. 2016. Efecto del rastrojo de Crotalaria spectabilis Roth en la germinación y crecimiento del Piatá Brachiaria brizantha cv. BRS Piatá, durante el establecimiento de pasturas sostenibles en San Carlos, Alajuela. Bachillerato en Ingeniería Agronómica. San José, Costa Rica. Universidad Estatal a Distancia. 58 pag

Di Rienzo J.A., Casanoves F., Balzarini M.G., González L., Tablada M., Robledo C.W. InfoStat versión 2015. Grupo InfoStat, FCA, Universidad Nacional de Córdoba, Argentina. URL http://www.infostat.com.ar

Hernán, M. Castellanos, A. 2011. Mineralización de nitrógeno en el suelo de zonas áridas y semiáridas. Sociedad Mexicana de la Ciencia del Suelo. Vol. 29. Núm. 3, Chapingo, México. 343-356 p. Disponible en: http:// www.redalyc.org/articulo.oa?id=57321283013.

INTA (Instituto Nacional de Tecnología Agropecuaria). 2016. Legumbres, una alternativa sustentable que enriquece el suelo. Argentina. URL http://intainforma.inta.gov.ar/?p=32074

Méndez, R. 2016. Finca Brenes. Atlas digital, Costa Rica. La Angelina, Cartago. Esc 1:60000

Obando, M. Rivera, D.; Bonilla, R.2013 Respuesta Fisiológica a la Fertilización por Azotobacter chroococcum AC1 y Fertilización Nitrogenada de Síntesis Sobre el Maíz (Zea mays L.) en Invernadero BioTecnología. 17(1).

Paredes, M.C. 2013. Fijación biológica de nitrógeno en leguminosas y gramíneas. Tesis Ing. En producción agropecuaria. Universidad Católica de Argentina. 115 p 